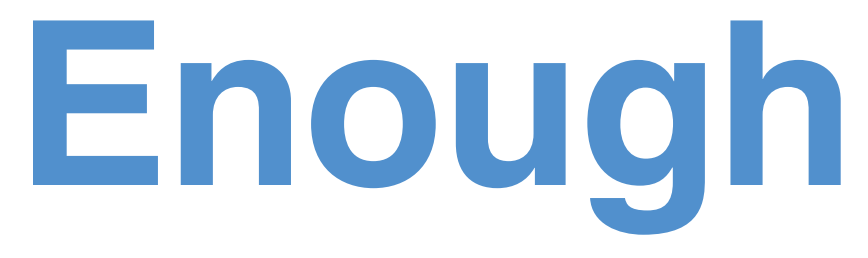

\title{
THE FAILURE OF THE LIVING WILL
}

\author{
by Angela Fagerlin and Carl E. SChneIder
}

In pursuit of the dream that patients' exercise of autonomy could extend beyond their span

of competence, living wills have passed from controversy to conventional wisdom, to widely

promoted policy. But the policy has not produced results, and should be abandoned.

\section{By their fruits ye shall know them.}

nough. The living will has failed, and it is time
to say so.

We should have known it would fail: A notable but neglected psychological literature always provided arresting reasons to expect the policy of living wills to misfire. Given their alluring potential, perhaps they were worth trying. But a crescendoing empirical literature and persistent clinical disappointments reveal that the rewards of the campaign to promote living wills do not justify its costs. Nor can any degree of tinkering ever make the living will an effective instrument of social policy.

As the evidence of failure has mounted, living wills have lost some of their friends. We offer systematic support for their change of heart. But living wills are still widely and confidently urged on patients, and they retain the allegiance of many

Angela Fagerlin and Carl E. Schneider, "Enough: The Failure of the Living Will," Hastings Center Report 34, no. 2 (2004): 30-42. bioethicists, doctors, nurses, social workers, and patients. For these loyal advocates, we offer systematic proof that such persistence in error is but the triumph of dogma over inquiry and hope over experience.

A note about the scope of our contentions: First, we reject only living wills, not durable powers of attorney. Second, there are excellent reasons to be skeptical of living wills on principle. For example, perhaps former selves should not be able to bind latter selves in the ways living wills contemplate. ${ }^{1}$ And many people do and perhaps should reject the view of patients, their families, and their communities that informs living wills. ${ }^{2}$ But we accept for the sake of argument that living wills desirably serve a strong version of patients' autonomy. We contend, nevertheless, that living wills do not and cannot achieve that goal.

And a stipulation: We do not propose the elimination of living wills. We can imagine recommending them to patients whose medical situation is plain, whose crisis is imminent, whose preferences 
are specific, strong, and delineable, and who have special reasons to prescribe their care. We argue on the level of public policy: In an attempt to extend patients' exercise of autonomy beyond their span of competence, resources have been lavished to make living wills routine and even universal. This policy has not produced results that recompense its costs, and it should therefore be renounced.

Living wills are a bioethical idea that has passed from controversy to conventional wisdom, from the counsel of academic journals to the com- have not granted living wills legal status, some courts have done so as a matter of common law, and where legislatures have granted them legal status, courts have cooperated with eager enthusiasm. ${ }^{6}$ Living wills have assumed special importance in states that prohibit terminating treatment in the absence of strong evidence of the patient's wishes. ${ }^{7}$ One supreme court summarized a common theme: "[A] written directive would provide the most concrete evidence of the patient's decisions, and we strongly urge all persons to create such a directive." ${ }^{8}$
Not only do legislatures, courts, administrative agencies, and professional associations promote the living will, but other groups unite with them. The Web abounds in sites advocating the living will to patients. ${ }^{12}$ The web site for our university's hospital plugs advance directives and suggests that it "is probably better to have written instructions because then everyone can read them and understand your wishes." 13

Our own experience in presenting this paper is that its thesis provokes some bioethicists to disbelief and in-

\section{If after so much propaganda so few of us have living wills, do we really want}

\section{them, or are we just saying what we think we ought to think and what}

\section{investigators want to hear?}

mands of law books, from professors' proposal to professional practice. Advance directives generally are embodied in federal policy by the Patient Self-Determination Act, which requires medical institutions to give patients information about their state's advance directives. In turn, the law of every state provides for advance directives, almost all states provide for living wills, and most states "have at least two statutes, one establishing a living will type directive, the other establishing a proxy or durable power of attorney for health care." 3 Not only are all these statutes very much in effect, but new legislative activity is constant. Senators Rockefeller, Collins, and Specter have introduced bills to "strengthen" the PSDA and living wills, ${ }^{4}$ and state legislatures continue to amend living will statutes and to enact new ones.

Courts and administrative agencies too have become advocates of living wills. The Veterans Administration has proposed a rule to encourage the use of advance directives, including living wills. ${ }^{5}$ Where legislatures
The grandees of law and medicine also give their benediction to the living will. The AMA's Council on Ethical and Judicial Affairs proclaims: "Physicians should encourage their patients to document their treatment preferences or to appoint a health care proxy with whom they can discuss their values regarding health care and treatment." The elite National Conference of Commissioners on Uniform State Laws continues to promulgate the Uniform Health-Care Decisions Act, a prestigious model statute that has been put into law in a still-growing number of states. Medical journals regularly admonish doctors and nurses to see that patients have advance directives, including living wills. ${ }^{10}$ Bar journals regularly admonish lawyers that their clients-all their clients-need advance directives, including living wills. ${ }^{11}$ Researchers demonstrate their conviction that living wills are important by the persistence of their studies of patients' attitudes toward living wills and ways of inveigling patients to sign them. dignation. It is as though they simply cannot bear to believe that living wills might not work. How can anything so intuitively right be proved so infuriatingly wrong? And indeed, bioethicists continue to investigate ways the living will might be extended (to deal with problems of the mentally ill and of minors, for example) and developed for other countries.

Although some sophisticated observers have long doubted the wisdom of living wills, ${ }^{14}$ proponents have tended to respond in one of three ways, all of which preserve an important role for living wills. First, proponents have supposed that the principal problem with living wills is that people just won't sign them. These proponents have persevered in the struggle to find ways of getting more people to sign up. ${ }^{15}$

Second, proponents have reasserted the usefulness of the living wills. For example, Norman Cantor, distingusted advocate of living wills, acknowledges that "(s)ome commentators doubt the utility or efficacy of advance directives," (by which he 
means the living will), but he concludes that "these objections don't obviate the importance of advance directives." 16 Other proponents are daunted by the criticisms of living wills but offer new justifications for them. Linda Emanuel, another eminent exponent of living wills, writes that "living wills can help doctors and patients talk about dying" and can thereby "open the door to a positive, caring approach to death." 17

Third, some proponents concede the weaknesses of the living will and the advantages of the durable power of attorney and then propose a durable power of attorney that incorporates a living will. That is, the forms they propose for establishing a durable power of attorney invite their authors to provide the kinds of instructions formerly confined to living wills. ${ }^{18}$

None of these responses fully grapples with the whole range of difficulties that confound the policy promoting living wills. In fairness, this is partly because the case against that policy has been made piecemeal and not in a full-fledged and full-throated analysis of the empirical literature on living wills.

In sum, the law has embraced the principle of living wills and cheerfully continues to this moment to expound and expand that principle. Doctors, nurses, hospitals, and lawyers are daily urged to convince their patients and clients to adopt living wills, and patients hear their virtues from many other sources besides. Some advocates of living wills have shifted the grounds for their support of living wills, but they persist in believing that they are useful. The time has come to investigate those policies and those hopes systematically. That is what this article attempts.

We ask an obvious but unasked question: What would it take for a regime of living wills to function as their advocates hope? First, people must have living wills. Second, they must decide what treatment they would want if incompetent. Third, they must accurately and lucidly state that preference. Fourth, their living wills must be available to people making decisions for a patient. Fifth, those people must grasp and heed the living will's instructions. These conditions are unmet and largely unmeetable.

\section{Do People Have Living Wills?}

$\Delta t$ the level of principle, living Awills have triumphed among the public as among the princes of medicine. People widely say they want a living will, and living wills have so much become conventional medical wisdom "that involvement in the process is being portrayed as a duty to physicians and others." ${ }^{19}$ Despite this, and despite decades of urging, most Americans lack them..$^{20}$ While most of us who need one have a property will, roughly 18 percent have living wills. ${ }^{21}$ The chronically or terminally ill are likelier to prepare living wills than the healthy, but even they do so fitfully. ${ }^{22}$ In one study of dialysis patients, for instance, only 35 percent had a living will, even though all of them thought living wills a "good idea." 23

Why do people flout the conventional wisdom? The flouters advance many explanations. ${ }^{24}$ They don't know enough about living wills, ${ }^{25}$ they think living wills hard to execute, ${ }^{26}$ they procrastinate, ${ }^{27}$ they hesitate to broach the topic to their doctors (as their doctors likewise hesitate). ${ }^{28}$ Some patients doubt they need a living will. Some think living wills are for the elderly or infirm and count themselves in neither group. ${ }^{29}$ Others suspect that living wills do not change the treatment people receive; 91 percent of the veterans in one study shared that suspicion. ${ }^{30}$ Many patients are content or even anxious to delegate decisions to their families, ${ }^{31}$ often because they care less what decisions are made than that they are made by people they trust. Some patients find living wills incompatible with their cultural traditions. ${ }^{32}$ Thus in the large SUPPORT and HELP studies, most patients pre- ferred to leave final resuscitation decisions to their family and physician instead of having their own preferences expressly followed $70.8 \%$ in HELP and $78.0 \%$ in SUPPORT). "This result is so striking that it is worth restating: not even a third of the HELP patients and hardly more than a fifth of the SUPPORT patients "would want their own preferences followed." 33

If people lacked living wills only because of ignorance, living wills might proliferate with education. But studies seem not to "support the speculations found in the literature that the low level of advance directives use is due primarily to a lack of information and encouragement from health care professionals and family members." ${ }^{34}$ Rather, there is considerable evidence "that the elderly's action of delaying execution of advance directives and deferring to others is a deliberate, if not an explicit, refusal to participate in the advance directives process." 35

The federal government has sought to propagate living wills through the Patient Self-Determination Act, ${ }^{36}$ which essentially requires medical institutions to inform patients about advance directives. However, "empirical studies demonstrate that: the PSDA has generally failed to foster a significant increase in advance directives use; it is being implemented by medical institutions and their personnel in a passive manner; and the involvement of physicians in its implementation is lacking." ${ }^{37}$ One commentator even thinks "the PSDA's legal requirements have become a ceiling instead of a floor." 38

In short, people have reasons, often substantial and estimable reasons, for eschewing living wills, reasons unlikely to be overcome by persuasion. Indeed, persuasion seems quickly to find its limits. Numerous studies indicate that without considerable intervention, approximately 20 percent of us complete living wills, but programs to propagate wills have mixed results. ${ }^{39}$ Some have achieved significant if still limited increases in 
the completion of living wills,,$^{40}$ while others have quite failed to do so. ${ }^{41}$

Thus we must ask: If after so much propaganda so few of us have living wills, do we really want them, or are we just saying what we think we ought to think and what investigators want to hear?

\section{Do People Know What They Will Want?}

Uppose, counterfactually, that peo$\checkmark$ ple executed living wills. For those documents to work, people would have to predict their preferences accurately. This is an ambitious demand. Even patients making contemporary decisions about contemporary illnesses are regularly daunted by the decisions' difficulty. They are human. We humans falter in gathering information, misunderstand and ignore what we gather, lack well-considered preferences to guide decisions, and rush headlong to choice. ${ }^{42}$ How much harder, then, is it to conjure up preferences for an unspecifiable future confronted with unidentifiable maladies with unpredictable treatments?

For example, people often misapprehend crucial background facts about their medical choices. Oregon
Even experience is a poor teacher: "Personal experience with illness ... and authoring an advance directive ... were not significantly associated with better knowledge about options." 43

Nor do people reliably know enough about illnesses and treatments to make prospective life-or-death decisions about them. To take one example from many, people grossly overestimate the effectiveness of CPR and in fact hardly know what it is. ${ }^{44}$ For such information, people must rely on doctors. But doctors convey that information wretchedly even to competent patients making contemporaneous decisions. Living wills can be executed without even consulting a doctor, ${ }^{45}$ and when doctors are consulted, the conversations are ordinarily short, vague, and tendentious. In the Tulsky study, for example, doctors only described either "dire scenarios ... in which few people, terminally ill or otherwise, would want treatment" or "situations in which patients could recover with proper treatment." 46

Let us put the point differently. The conventional-legal and ethical wisdom-insists that candidates for even a flu shot give "informed consent." And that wisdom has increas-
Not only do people regularly know too little when they sign a living will, but often (again, we're human) they analyze their choices only superficially before placing them in the time capsule. An ocean of evidence affirms that answers are shaped by the way questions are asked. Preferences about treatments are influenced by factors like whether success or failure rates are used, ${ }^{48}$ the level of detail employed, ${ }^{49}$ and whether longor short-term consequences are explained first. ${ }^{50}$ Thus in one study, "201 elderly subjects opted for the intervention $12 \%$ of the time when it was presented negatively, $18 \%$ of the time when it was phrased as in an advance directive already in use, and $30 \%$ of the time when it was phrased positively. Seventy-seven percent of the subjects changed their minds at least once when given the same case scenario but a different description of the intervention." 51

If patients have trouble with contemporaneous decisions, how much more trouble must they have with prospective ones. For such decisions to be "true," patients' preferences must be reasonably stable. Surprisingly often, they are not. A famous study of eighteen women in a "natural

\section{Even patients making contemporary decisions about contemporary}

\section{illnesses are regularly daunted by the decisions' difficulty. How much harder,}

\section{then, is it to conjure up preferences for an unspecifiable future confronted}

\section{with unidentifiable maladies with unpredictable treatments?}

has made medical policy in fresh and controversial ways, has recently had two referenda on assisted suicide, and alone has legalized it. Presumably, then, its citizens are especially knowledgeable. But only 46 percent of them knew that patients may legally withdraw life-sustaining treatment. ingly raised the standards for disclosure. $^{47}$ If we applied those standards to the information patients have before making the astonishing catalog of momentous choices living wills can embody, the conventional wisdom would be left shivering with indignation. childbirth" class found that preferences about anesthesia and avoiding pain were relatively stable before childbirth, but at "the beginning of active labor $(4-5 \mathrm{~cm}$ dilation) there was a shift in the preference toward avoiding labor pains. ... During the transition phase of labor $(8-10 \mathrm{~cm})$ 
the values remained relatively stable, but then ... the mothers' preferences shifted again at postpartum toward avoiding the use of anesthesia during the delivery of her next child." 52 And not only are preferences surprisingly labile, but people have trouble recognizing that their views have changed. ${ }^{53}$ This makes it less likely they will amend their living wills as their opinions develop and more likely that their living wills will treasonously misrepresent their wishes.

Instability matters. The healthy may incautiously prefer death to disability. Once stricken, competent patients can test and reject that preference. They often do. ${ }^{54}$ Thus Wilfrid Sheed "quickly learned [that] cancer, even more than polio, has a disarming way of bargaining downward, beginning with your whole estate and then letting you keep the game warden's cottage or badminton court; and by the time it has tried to frighten you to death and threatened to take away your very existence, you'd be amazed at how little you're willing to settle for." 55

At least sixteen studies have investigated the stability of people's preferences for life-sustaining treatment. ${ }^{56}$ A meta-analysis of eleven of these studies found that the stability of patients' preferences was 71 percent (the range was 57 percent to 89 percent). ${ }^{57}$ Although stability depended on numerous factors (including the illness, the treatment, and demographic variables), the bottom line is that, over periods as short as two years, almost one-third of preferences for life-sustaining medical treatment changed. More particularly, illness and hospitalization change people's preferences for life-sustaining treatments. ${ }^{58}$ In a prospective study, the desire for life-sustaining treatment declined significantly after hospitalization but returned almost to its original level three to six months later. ${ }^{59}$ Another study concluded that the "will to live is highly unstable among terminally ill cancer patients." ${ }^{60}$ The authors thought their findings "perhaps not surprising, given that only $10-14 \%$ of individuals who survive a suicide attempt commit suicide during the next 10 years, which suggests that a desire to die is inherently changeable."

The consistent finding that interest in life-sustaining treatment shifts over time and across contexts coincides tellingly with research charting people's struggles to predict their own tastes, behavior, and emotions even over short periods and under familiar circumstances. ${ }^{61}$ People mispredict what poster they will like, ${ }^{62}$ how much they will buy at the grocery store, ${ }^{63}$ how sublimely they will enjoy an ice cream, ${ }^{64}$ and how they will adjust to tenure decisions. ${ }^{65}$ And people "miswant" for numerous reasons. ${ }^{66}$ They imagine a different event from the one that actually occurs, nurture inaccurate theories about what gives them pleasure, ${ }^{67}$ forget they might outwit misery, concentrate on salient negative events and ignore offsetting happier ones, ${ }^{68}$ and misgauge the effect of physiological sensations like pain. ${ }^{69}$ Given this rich stew of research on people's missteps in predicting their tastes generally, we should expect misapprehensions about end-of-life preferences. Indeed, those preferences should be especially volatile, since people lack experience deciding to die.

\section{Can People Articulate What They Want?}

Suppose, arguendo, that patients $\checkmark$ regularly made sound choices about future treatments and write living wills. Can they articulate their choices accurately? This question is crucially unrealistic, of course, because the assumption is false. People have trouble reaching well-considered decisions, and you cannot state clearly on paper what is muddled in your mind. And indeed people do, for instance, issue mutually inconsistent instructions in living wills. ${ }^{70}$

But assume this difficulty away and the problem of articulation persists. In one sense, the best way to divine patients' preferences is to have them write their own living wills to give surrogates the patient's gloriously unmediated voice. This is not a practical policy. Too many people are functionally illiterate, ${ }^{71}$ and most of the literate cannot express themselves clearly in writing. It's hard, even for the expert writer. Furthermore, most people know too little about their choices to cover all the relevant subjects. Hence living wills are generally forms that demand little writing. But the forms have failed. For example, "several studies suggest that even those patients who have completed $\mathrm{AD}$ forms ... may not fully understand the function of the form or its language." 72 Living wills routinely baffle patients with their

\section{"syntactic complexity, concept density, abstractness, organization, coherence, sequence of ideas, page format, length of line of print, length of paragraph, punctuation, illustrations, color, and reader in- terest." Unfortunately, most ad- vance directive forms . . . often have neither a reasonable scope nor depth. They do not ask all the right questions and they do not ask those questions in a manner that elicits clear responses. ${ }^{73}$}

Doctors and lawyers who believe their clients are all above average should ask them what their living will says. One of us (CES) has tried the experiment. The modal answer is, in its entirety: "It says I don't want to be a vegetable."

No doubt the forms could be improved, but not enough to matter. The world abounds in dreadfully drafted forms because writing complex instructions for the future is crushingly difficult. Statutes read horribly because their authors are struggling to (1) work out exactly what rule they want, (2) imagine all the circumstances in which it might apply, and (3) find language to specify all those but only those circumstances. Each task is ultimately impossible, which is why statutes explicitly or implicitly confide their enforcers with some discretion and why 
courts must interpret-rewrite?statutes. However, these skills and resources are not available to physicians or surrogates.

One might retort that property wills work and that living wills are not that far removed from property wills. But wills work as well as they do to distribute property because their scope is - compared to living willsnarrow and routinized. Most people have little property to distribute and few plausible heirs. As property accumulates and ambitions swell, problems proliferate. Many of them are resolvable because experts-lawyersexclusively draft and interpret wills. Lawyers have been experimenting for centuries with testamentary language in a process which has produced standard formulas with predictable meanings and standard ways of distributing property into which testators are channeled. Finally, if testators didn't say it clearly enough in the right probing discussions between doctor and patient. However, the demand for specificity forced patients to address more questions than they could comprehend. So, generalities were insufficiently specific and insufficiently considered. Specifics were insufficiently general and perhaps still insufficiently considered. What was a doctor-or lawyer-to do? Behold the "values history," a disquisition on the patient's supposed overarching beliefs from which to infer answers to specific questions. ${ }^{74}$ That patients can be induced to trek through these interminable and imponderable documents is unproved and unlikely. That useful conclusions can be drawn from the platitudes they evoke is false. As Justice Holmes knew, "General propositions do not decide concrete cases."75

The lessons of this story are that drafting instructions is harder than proponents of living wills seem to be- not. This should be no surprise, for long can be the road from the drafteer's chair to the ICU bed.

First, the living will may be signed years before it is used, and its existence and location may vanish in the mists of time. ${ }^{76}$ Roughly half of all living wills are drawn up by lawyers and must somehow reach the hospital, and 62 percent of patients do not give their living will to their physician. ${ }^{77}$ On admission to the hospital, patients can be too assailed and anxious to recall and mention their advance directives. ${ }^{78}$ Admission clerks can be harried, neglectful, and loath to ask patients awkward questions.

Thus when a team of researchers reviewed the charts of 182 patients who had completed a living will before being hospitalized, they found that only 26 percent of the charts accurately recorded information about those directives, ${ }^{79}$ and only 16 percent of the charts contained the form.

\section{Were living wills too general? Make them specific. Were they "one size fits}

\section{all"? Make them elaborate questionnaires. Were they uncritically signed? "Re-}

\section{quire" probing discussions between doctor and patient. . . .}

\section{Behold the "values history."}

words and following the right procedures, courts coolly ignore their wishes and substitute default rules.

The lamentable history of the living will demonstrates just how recalcitrant these problems are. There have been, essentially, three generations of living wills. At first, they stated fatuously general desires in absurdly general terms. As the vacuity of over-generality became clear, advocates of living wills did the obvious: Were living wills too general? Make them specific. Were they "one size fits all"? Make them elaborate questionnaires. Were they uncritically signed? "Require" lieve and that when you move toward one blessing in structuring these documents, you walk away from another. The failure to devise workable forms is not a failure of effort or intelligence. It is a consequence of attempting the impossible.

\section{Where Is the Living Will?}

uppose that, mirabile dictu, people $\checkmark$ executed living wills, knew what they will want, and could say it. That will not matter unless the living will reaches the people responsible for the incompetent patient. Often, it does
And in another study only 35 percent of the nursing home patients who were transferred to the hospital had their living wills with them. ${ }^{80}$

\section{Will Proxies Read It Accurately?}

Cuppose, per impossibile, that pa$\checkmark$ tients wrote living wills, correctly anticipated their preferences, articulated their desires lucidly, and conveyed their document to its interpreters. How acutely will the interpreters analyze their instructions? Living wills are not self-executing: some- 
one must decide whether the patient is incompetent, whether a medical situation described in the living will has arisen, and what the living will then commands.

Usually, the patient's intimates will be central among a living will's interpreters. We might hope that intimates already know the patient's mind, so that only modest demands need be made on their interpreting skills. But many studies have asked such surrogates to predict what treatment the patient would choose. ${ }^{81}$ Across these studies, approximately 70 percent of the predictions were correct-not inspiring success for life and death decisions.

Do living wills help? We know of only one study that addresses that question. In a randomized trial, researchers asked elderly patients to complete a disease- and treatmentbased or a value-based living will. ${ }^{82} \mathrm{~A}$ control group of elderly patients completed no living will. The surrogates were generally spouses or children who had known the patient for decades. Surrogates who were not able to consult their loved one's living will predicted patients' preferences about 70 percent of the time. Strikingly, surrogates who consulted the living will did no better than surrogates denied it. Nor were surrogates more successful when they discussed living wills with patients just before their prediction.

What is more, a similar study found that primary care physicians' predictions were similarly unimproved by providing them with patients' advance directives. ${ }^{83}$ On the other hand, emergency room doctors (complete strangers) given a living will more accurately predicted patients' preferences than ER doctors without one. ${ }^{84}$

\section{Do Living Wills Alter Patient Care?}

ur survey of the mounting empirical evidence shows that none of the five requisites to making living wills successful social policy is met now or is likely to be. The program has failed, and indeed is impossible.

That impossibility is confirmed by studies of how living wills are implemented, which show that living wills seem not to affect patients' treatments. For instance, one study concluded that living wills "do not influence the level of medical care overall. This finding was manifested in the quantitatively equal use of diagnostic testing, operations, and invasive hemodynamic monitoring among patients with and without advance directives. Hospital and ICU lengths of stay, as well as health care costs, were also similar for patients with and without advance directive statements." 85 Another study found that in thirty of thirty-nine cases in which a patient was incompetent and the living will was in the patient's medical record, the surrogate decisionmaker was not the person the patient had appointed. ${ }^{86}$ In yet a third study, a quarter of the patients received care that was inconsistent with their living will. ${ }^{87}$

But all this is normal. Harry Truman rightly predicted that his successor would "sit here, and he'll say, 'Do this! Do that!' And nothing will happen. Poor Ike-it won't be a bit like the army. He'll find it very frustrating." (Of course, the army isn't like the army either, as Captain Truman surely knew.) Indeed, the whole law of bioethics often seems a whited sepulchre for slaughtered hopes, for its policies have repeatedly fallen woefully short of their purposes. Informed consent is a "fairytale." 88 Programs to increase organ donation have persistently disappointed. Laws regulating DNR orders are hardly better. Legal definitions of brain death are misunderstood by astonishing numbers of doctors and nurses. And so on. ${ }^{89}$

But why don't living wills affect care?90 Joan Teno and colleagues saw no evidence "that a physician unilaterally decided to ignore or disregard an AD." Rather, there was "a complex interaction of . . . three themes." First (as we have emphasized), "the con- tents of ADs were vague and difficult to apply to current clinical situations." The imprecision of living wills not only stymies interpreters, it exacerbates their natural tendency to read documents in light of their own preferences. Thus "(e)ven with the therapy-specific AD accompanied by designation of a proxy and prior patientphysician discussion, the proportion of physicians who were willing to withhold therapies was quite variable: cardiopulmonary resuscitation, $100 \%$; administration of artificial nutrition and hydration, $82 \%$; administration of antibiotics, $80 \%$; simple tests, 70\%; and administration of pain medication, 13\%." 91

Second, the Teno team found that "patients were not seen as 'absolutely, hopelessly ill,' and thus, it was never considered the time to invoke the AD." Living wills typically operate when patients become terminally ill, but neither doctors nor families lightly conclude patients are dying, especially when that means ending treatment. And understandably. For instance, "on the day before death, the median prognosis for patients with heart failure is still a $50 \%$ chance to live 6 more months because patients with heart failure typically die quickly from an unpredictable complication like arrhythmia or infection." 92 So by the time doctors and families finally conclude the patient is dying, the patient's condition is already so dire that treatment looks pointless quite apart from any living will. "In all cases in which life-sustaining treatment was withheld or withdrawn, this decision was made after a trial of life-sustaining treatment and at a time when the patient was seen as 'absolutely, hopelessly ill' or 'actively dying.' Until patients crossed this threshold, ADs were not seen as applicable." Thus "it is not surprising that our previous research has shown that those with ADs did not differ in timing of DNR orders or patterns of resource utilization from those without ADs." 93

Third, "family members or the surrogate designated in a [durable power of attorney] were not available, 
were ineffectual, or were overwhelmed with their own concerns and did not effectively advocate for the patient." Family members are crucial surrogates because they should be: patients commonly want them to be; they commonly want to be; they specially cherish the patient's interests. Doctors ordinarily assume families know the patient's situation and preferences and may not relish responsibility for life-and-death decisions, and doctors intent on avoiding litigation may realize that the only plausible plaintiffs are families. The family, however, may not direct atten- they might have other benefits that justify their costs. There are three promising candidates.

First, living wills might stimulate conversation between doctor and patient about terminal treatment. However, at least one study finds little association between patients' reports of executing an advance directive and their reports of such conversations. ${ }^{95}$ Nor do these conversations, when they occur, appear satisfactory. ${ }^{96}$ James Tulsky and colleagues asked experienced clinicians who had relationships with patients who were over sixty-five or seriously ill to "discuss
Nor were the conversations conspicuously informative: "Physicians used vague language to describe scenarios, asking what patients would want if they became 'very, very sick' or 'had something that was very serious.' . . ." Further, "[v]arious qualitative terms were used loosely to describe outcome probabilities." In addition, these brief conversations considered almost exclusively the two ends of the continuum-the most hopeless and the most hopeful cases. Conversations tended to ignore "the more common, less clear-cut predicaments surrounding end-of-life care."

\title{
We should abjure programs intended to cajole everyone into signing
}

\section{living wills. We should repeal the PSDA, which was passed with arrant and}

\section{arrogant indifference to its effectiveness and its costs and which today}

\author{
imposes accumulating paperwork and administrative
}

\section{expense for paltry rewards.}

tion to the advance directive and may not insist on its enforcement. In fact, surrogates may be guided by either their own treatment preferences or an urgent desire to keep their beloved alive. $^{94}$

In sum, not only are we awash in evidence that the prerequisites for a successful living wills policy are unachievable, but there is direct evidence that living wills regularly fail to have their intended effect. That failure is confirmed by the numerous convincing explanations for it. And if living wills do not affect treatment, they do not work.

Do Living Wills Have Beneficial Side Effects?

$\checkmark$ ven if living wills do not effectively promote patients' autonomy, advance directives in whatever way you think is appropriate" with them. Although the doctors knew they were being taped, the conversations were impressively short and one-sided: The median discussion "lasted $5.6 \mathrm{~min}$ utes (range, 0.9 to 15.0 minutes.) Physicians spoke for a median of 3.9 minutes (range, 0.6 to 10.9 minutes), and patients spoke for the remaining 1.7 minutes (range, 0.3 to $9.6 \mathrm{~min}$ utes). . . . Usually, the conversation ended without any specific follow-up plan." The "(p)atients' personal values, goals for care, and reasons for treatment preferences were discussed in $71 \%$ of cases and were explicitly elicited by $34 \%$ of physicians." But doctors commonly "did not explore the reasons for patient's preferences and merely determined whether they wanted specific interventions."97
True, the patients all thought "their physicians 'did a good job talking about the issues," but this only suggests that patients did not understand how little they were told.

The second candidate for beneficial side effect arises from evidence that living wills may comfort patients and surrogates. People with a living will apparently gain confidence that their surrogates will understand their preferences and will implement them comfortably, and the surrogates concur. ${ }^{98}$ Improved satisfaction with decisions was also a rare positive effect of the SUPPORT study (which devoted enormous resources to improving end of life decisions and care but made dismayingly little difference). ${ }^{99}$ In another study, living wills reduced the stress and unhappiness of family members who had recently with- 
drawn life support from a relative. ${ }^{100}$ But even if living wills make patients and surrogates more confident and comfortable, those qualities are apparently unrelated to the accuracy of surrogates' decisions. Thus we are left with the irony that one of the best arguments for a tool for enhancing people's autonomy is that it deceives them into confidence.

Third, because living wills generally constrain treatment, they might reduce the onerous costs of terminal illness. Although several studies associated living wills with small decreases in those costs, ${ }^{101}$ several studies have reached the opposite conclusion. ${ }^{102}$ The old Scotch verdict, "not proven," seems apt.

\section{The Costs}

'here is no free living will, and the better (or at least more thorough surance and when we are spending more of our gross domestic product on health care than comparable countries without buying commensurately better health. If programs to promote and provide living wills showed signs of achieving the goals cherished for them, we would have to decide whether their valuable but incalculable rewards exceeded their diffuse but daunting costs. However, since those programs have failed, their costs plainly outweigh their benefits.

\section{What Is To Be Done?}

T iving wills attempt what undertakers like to call "pre-need planning," and on inspection they are as otiose as the mortuary version. Critically, empiricists cannot show that advance directives affect care. This is damning, but were it our only evi- do not have living wills. And they often have considered and considerable reasons for their choice. Second, people who sign living wills have generally not thought through its instructions in a way we should want for life-and-death decisions. Nor can we expect people to make thoughtful and stable decisions about so complex a question so far in the future. Third, drafters of living wills have failed to offer people the means to articulate their preferences accurately. And the fault lies primarily not with the drafters; it lies with the inherent impossibility of living wills' task. Fourth, living wills too often do not reach the people actually making decisions for incompetent patients. This is the most remediable of the five problems, but it is remediable only with unsustainable effort and unjustifiable expense. Fifth, living wills seem not to increase the accuracy with

\title{
Patients anxious to control future medical decisions should be told about
}

\section{durable powers of attorney, which have many advantages over}

\author{
living wills. As these things go, they are simple, direct, modest,
}

\section{straightforward, and thrifty.}

and careful) the living will, the more it costs. Living wills consume patient's time and energy. When doctors or lawyers help, costs soar. On a broader view, Jeremy Sugarman and colleagues estimated that the Patient Self-Determination Act imposed on all hospitals a start-up cost of $\$ 101,569,922$ and imposed on one hospital (Johns Hopkins) initial costs of $\$ 114,528 .{ }^{103}$ These figures omit the expenses, paid even as we write and you read, of administering the program. And this money has bought only pro forma compliance.

These are real costs incurred when over 40 million people lack health in- dence, perhaps we might not be weary in well doing: for in due season we might reap, if we faint not. However, our survey of the evidence suggests that living wills fail not for want of effort, or education, or intelligence, or good will, but because of stubborn traits of human psychology and persistent features of social organization.

Thus when we reviewed the five conditions for a successful program of living wills, we encountered evidence that not one condition has been achieved or, we think, can be. First, despite the millions of dollars lavished on propaganda, most people which surrogates identify patients' preferences. And the reasons we surveyed when we explained why living wills do not affect patients' care suggest that these problems are insurmountable.

The cost-benefit analysis here is simple: If living wills lack detectable benefits, they cannot justify any cost, much less the considerable costs they now exact. Any attempt to increase their incidence and their availability to surrogates must be expensive. And the evidence suggests that broader use of living wills can actually disserve rather than promote patients' autonomy: If, as we have argued, patients 
sign living wills without adequate reflection, lack necessary information, and have fluctuating preferences anyway, then living wills will not lead surrogates to make the choices patients would have wanted. Thus, as Pope suggests, the "PSDA, rather than promoting autonomy has 'done a disservice to most real patients and their families and caregivers.' It has promoted the execution of uninformed and under-informed advance directives, and has undermined, not protected, self-determination." 104

If living wills have failed, we must say so. We must say so to patients. If we believe our declamations about truth-telling, we should frankly warn patients how faint is the chance that living wills can have their intended effect. More broadly, we should abjure programs intended to cajole everyone into signing living wills. We should also repeal the PSDA, which was passed with arrant and arrogant indifference to its effectiveness and its costs and which today imposes accumulating paperwork and administrative expense for paltry rewards. ${ }^{105}$

Of course we recognize the problems presented by the decisions that must be made for incompetent patients, and our counsel is not wholly negative. Patients anxious to control future medical decisions should be told about durable powers of attorney. These surely do not guarantee patients that their wishes will blossom into fact, but nothing does. What matters is that powers of attorney have advantages over living wills. First, the choices that powers of attorney demand of patients are relatively few, familiar, and simple. Second, a regime of powers of attorney requires little change from current practice, in which family members ordinarily act informally for incompetent patients. Third, powers of attorney probably improve decisions for patients, since surrogates know more at the time of the decision than patients can know in advance. Fourth, powers of attorney are cheap; they require only a simple form easily filled out with little advice. Fifth, powers of attorney can be supplemented by legislation (already in force in some states) akin to statutes of intestacy. These statutes specify who is to act for incompetent patients who have not specified a surrogate. In short, durable powers of attorney are-as these things go- - simple, direct, modest, straightforward, and thrifty.

In social policy as in medicine, plausible notions can turn out to be bad ideas. Bad ideas should be renounced. Bloodletting once seemed plausible, but when it demonstrably failed, the course of wisdom was to abandon it, not to insist on its virtues and to scrounge for alternative justifications for it. Living wills were praised and peddled before they were fully developed, much less studied. They have now failed repeated tests of practice. It is time to say, "enough."

\section{Disclaimer}

This report and its conclusions are the opinions of the authors and do not necessarily represent those of the Department of Veterans Affairs.

\section{Acknowledgments}

The authors thank Renée Anspach, Kristen Coppola, Jane Foreman, Susan Dorr Goold, Marsha Garrison, Joel Howell, and Rebecca Walker for their intelligent comments on an earlier draft of this paper. We also thank Tammy Savercool for her assistance in preparing the manuscript. Angela Fagerlin thanks members of the ADVANCE Project team for their numerous contributions to her thinking on this topic.

\section{References}

1. R. Dresser, "Missing Persons: Legal Perceptions of Incompetent Patients," Rutgers Law Review 46 (1994): 609-695.

2. J. Lynn, "Why I Don't Have a Living Will," Law, Medicine \& Health Care 19, nos. 1-2 (1991): 101-104.

3. C.P. Sabatino, "End-of-Life Legal Trends," ABA Commission on Legal Problems of the Elderly 2, (2000).

4. Health Care Assurance of 2001. S. 26. 107th Congress ed; 2001; The Advance Planning and Compassionate Care Act of 1999. S. 628. 106th Congress ed; 1999.
5. 38 CFR Part 17 RIN. 2900-AJ28. November 2, 1998.

6. Knight v. Beverly Health Care. 820 S2d 92; 2001

7. See Conservatorship of Wendland, where the California Supreme Court construed the state's Health Care Decisions Law as "requiring clear and convincing evidence of a conscious conservatee's wish to justify withholding life-sustaining treatment" but held that decision did not affect patients who had left "formal directions for health care." 28 P.3d 151; 2001.

8. In re Martin. 538 NW2d 399; Mich 1995.

9. Council on Ethical and Judicial Affairs of the American Medical Association, Surrogate Decision Making E8.081. http://www.ama-assn.org

10. P.J. Aitken, "Incorporating Advance Care Planning into Family Practice," American Family Physician," 59 (1999): 605-620; A.O. Calvin and A.P. Clark, "How Are You Facilitating Advance Directives in Your Clinical Nurse Specialist Practice?" Clinical Nurse Specialist 16, no. 6 (2002): 292-94.

11. A document that " $[\mathrm{g}]$ ives person responsible for making medical decisions greater information, specificity and insight about your specific health-care related decisions, wishes, and objectives" is "A MUST FOR NEARLY EVERYONE" (P. A. Meints, "A Trust and Estate Planning Questionnaire for Families with Minor Children," The Practical Tax Lawyer 16, no. 1, [2001]: 33). Providing living wills has also become a pro bono activity. "Wills on Wheels was established by a committee of paralegals and consulting attorneys determined to provide. . . low-income adults with simple wills and living wills" (J.M. Price, "pro Bono and Paralegals: Helping to Make a Difference" Colorado Lawyer (September 30, 2000), 55-56.

12. See www.aarp.org/confacts/programs/endoflife.html.

13. The form's critical paragraph reads; "My desires concerning medical treatment are-." Then it leaves fourteen bland lines the patient may fill in. Available at www.med.umich.edu/1libr/aha/umlegal04.htm.

14. R. Dresser, "Precommitment: A Misguided Strategy for Securing Death with Dignity," Texas Law Review 81 (2003): 1823-1847.

15. A.R. Eiser and M.D. Weiss, "The Underachieving Advance Directive: Recommendations for Increasing Advance Directive Completion," American Journal of Bioethics 1 (2001): 1-5.

16. N.L. Cantor, "Twenty-five Years after Quinlan: A Review of the Jurisprudence of Death and Dying," Journal of Law, Medicine \& Ethics 29 (2001): 182-96. 
17. L. Emanuel, "Living Wills Can Help Doctors and Patients Talk about Dying," Western Journal of Medicine 173 (2000): 368.

18. For example, the form provided by a consortium of the American Bar Association, the American Medical Association, and the American Association of Retired Persons "combines and expands the traditional Living Will and Health Care Power of Attorney into a single, comprehensive document" (http://www.ama-assn.org/public/booklets/livgwill.htm).

19. D.M. High, "Why Are Elderly People Not Using Advance Directives?” Journal of Aging and Health 5, no. 4 (1993): $497-$ 515 .

20. L.L. Emanuel, "Advance Directives for Medical Care; Reply." NEJM 325 (1991): 1256; N.L. Cantor, "Making Advance Directives Meaningful," Psychology, Public Policy, and Law 4, no. 3 (1998): 62952; D.M. Cox and G.A. Sachs, "Advance Directives and the Patient Self-Determination Act," Clinics in Geriatric Medicine 10 (1994): 431-43; G.A.D. Havens, "Differences in the Execution/Nonexecution of Advance Directives by Community Dwelling Adults," Research in Nursing and Health 23 (2000): 319-33; D.M. High, "Advance Directives and the Elderly: A Study of Intervention Strategies to Increase Use," Gerontologist 33, no. 3 (1993): 34249; S.H. Miles, R. Koepp, and E.P. Weber, "Advance End-of-Life Treatment Planning: A Research Review," Archives of Internal Medicine 156, no. 10 (1996): 1062-1068; S.R. Steiber, "Right to Die: Public Balks at Deciding for Others," Hospitals 61 (1987): 572; J. Teno et al., "Do Advance Directives Provide Instructions that Direct Care? SUPPORT Investigators. Study to Understand Prognoses and Preferences for Outcomes and Risks of Treatment," Journal of the American Geriatrics Society 45, no. 4 (1997): 508-512.

21. Emanuel, "Advance Directives for Medical Care; Reply."

22. Miles, Koepp, and Weber, "Advance End-of-Life Treatment Planning"; J.L. Holley et al., "Factors Influencing Dialysis Patients' Completion of Advance Directives," American Journal of Kidney Diseases 30, no. 3 (1997): 356-60; L.C. Hanson and E. Rodgman, "The Use of Living Wills at the End of Life: A National Study," Archives of Internal Medicine 156, no. 9 (1996): 10181022; J.M. Teno et al., "Do Advance Directives Provide Instructions that Direct Care? SUPPORT Investigators. Study to Understand Prognoses and Preferences for Outcomes and Risks of Treatment," Journal of the American Geriatrics Society 45, no. 4 (1997): 508-512.
23. Holley et al., "Factors Influencing Dialysis Patients' Completion of Advance Directives."

24. Cox and Sachs, "Advance Directives and the Patient Self-Determination Act"; Miles, Koepp, and Weber, "Advance Endof-Life Treatment Planning”; D.M. High, "All in the Family: Extended Autonomy and expectations in Surrogate Health Care Decision-Making," Gerontologist 28 (suppl) (1988): 46-51.

25. L.L. Emanuel and E.J. Emanuel, "The Medical Directive: A New Comprehensive Advance Care Document," JAMA 261 (1989): 3288-93.

26. High, "Advance Directives and the Elderly"; J.M. Roe et al., "Durable Power of Attorney for Health care: A Survey of Senior Center Participants," Archives of Internal Medicine 152 (1992): 292-96.

27. High, "Why Are Elderly People Not Using Advance Directives?"; Roe et al., "Durable Power of Attorney for Health care."

28. High, "Why Are Elderly People Not Using Advance Directives?"; Roe et al., "Durable Power of Attorney for Health care"; E.J. Emanuel, L.L. Emanuel, and D. Orentlicher, "Advance Directives," JAMA 266 (1991): 2563-63; G.A. Sachs, C.B. Stocking, and S.H. Miles, "Empowerment of the older patient? A Randomized, Controlled Trial to Increase Discussion and Use of Advance Directives," Journal of the American Geriatrics Society 40, no. 3 (1992): 26973; L.L. Brunetti, S.D. Carperos, and R.E. Westlund, "Physicians' Attitudes towards Living Wills and Cardiopulmonary Resuscitation," Journal of General Internal Medicine 6 (1991): 323-29; T.E. Finucane et al., "Planning with Elderly Outpatients for Contingencies of Severe Illness: A Survey and Clinical Trial," Journal of General Internal Medicine 3, no. 4 (1988): 322-25; B. Lo, G.A. McLeod, and G. Saika, "Patient Attitudes to Discussing Life-sustaining Treatment," Archives of Internal Medicine 146, no. 8 (1986): 1613-15; R. Yamada et al., "A Multimedia Intervention on Cardiopulmonary Resuscitation and Advance Directives," Journal of General Internal Medicine 14 (1999): 559-63.

29. Cox and Sachs, "Advance Directives and the Patient Self-Determination Act"; L.L. Emanuel and E. Emanuel, "Advance Directives," Annals of Internal Medicine 116 (1992): 348-49; B.B. Ott, "Advance Directives: The Emerging Body of Research," American Journal of Critical Care 8 (1999): 514-19.

30. J. Sugarman, M. Weinberger, and G. Samsa, "Factors Associated with Veterans' Decisions about Living Wills," Archives of Internal Medicine 152 (1992): 343-47.
31. Cox and Sachs, "Advance Directives and the Patient Self-Determination Act"; Holley et al., "Factors Influencing Dialysis Patients' Completion of Advance Directives," High, "All in the Family"; Roe et al., "Durable Power of Attorney for Health care"; Ott, "Advance Directives"; N.A. Hawkins et al., "Do Patients Want to Micro-manage Their Own Deaths? Process Preferences, Values and Goals in End-ofLife Medical Decision Making," Unpublished manuscript. P.B. Terry et al., "End-ofLife Decision Making: When Patients and Surrogates Disagree," Journal of Clinical Ethics 10, no. 4 (1999): 286-93.

32. J. Carrese and L. Rhodes, "Western Bioethics on the Navajo Reservation: Benefit or Harm?" JAMA 274 (1995): 826-29; L.J. Blackhall et al., "Ethnicity and Attitudes toward Patient Autonomy," JAMA 274 (1995): 820-25.

33. C.M. Puchalski et al., Patients Who Want their Family and Physician to Make Resuscitation Decisions for Them: Observations from SUPPORT and HELP; JAGS 48 (2000): S84.

34. High, "Why Are Elderly People Not Using Advance Directives?"

35. Ibid.

36. Patient Self-Determination Act of 1990. of the Omnibus Reconsiliation Act of 1990.

37. J.L. Yates and H.R. Glick, "The Failed Patient Self-Determination Act and Policy Alternatives for the Right to Die," Journal of Aging and Social Policy 29 (1997): 29, 31.

38. M.T. Pope, "The Maladaptation of Miranda to Advance Directives: A Critique of the Implementation of the Patient SelfDetermination Act," Health Matrix 9 (1999): 139

39. Cox and Sachs, "Advance Directives and the Patient Self-Determinaction Act."

40. J. Hare and C. Nelson, "Will Outpatients Complete Living Wills? A Comparison of Two Interventions," Journal of General Internal Medicine 6 (1991): 41-46.

41. Yamada et al., "A Multimedia Intervention on Cardiopulmonary Resuscitation and Advance Directives"; G.A. Sachs, S.H. Miles, and R.A. Levin, "Limiting Resuscitation: Emerging Policy in the Emergency Medical System," Annals of Internal Medicine 114 (1991): 151-54.

42. C.E. Schneider, The Practice of $A u-$ tonomy: Patients, Doctors, and Medical Decisions (New York: Oxford University Press, 1998).

43. M.J. Silveira et al., "Patient's Knowledge of Options at the End of Life: Ignorance in the Face of Death," JAMA 284 (2000): 2483, 2486-87. 
44. Yamada et al., "A Multimedia Intervention on Cardiopulmonary Resuscitation and Advance Directives"; S.H. Miles, "Advanced Directives to Limit Treatment: The Need for Portability," Journal of the American Geriatrics Society 35, no. 1 (1987): 7476; K.M. Coppola et al., "Perceived Benefits and Burdens of Life-Sustaining Treatments: Differences among Elderly Adults, Physicians, and Young Adults," Journal of Ethics, Law, and Aging 4, no. 1 (1998): 3-13.

45. Roe et al., "Durable Power of Attorney for Health care."

46. J.A. Tulsky et al., "Opening the Black Box: How Do Physicians Communicate about Advance Directives?" Annals of Internal Medicine 129 (1998): 441, 444.

47. C.E. Schneider and M. Farrell, Information, Decisions, and the Limits of Informed Consent (New York: Oxford University Press, 2000).

48. B.J. McNeil et al., "On the Elicitation of Preferences for Alternative Therapies," NEJM 306 (1982): 1259-62.

49. T.R. Malloy et al., "The Influence of Treatment Descriptions on Advance Medical Directive Decisions," Journal of the American Geriatrics Society 40, no. 12 (1992): 1255-60; D.J. Mazur and D.H. Hickman, "Patient Preferences: Survival versus Quality-of-Life Considerations," Journal of General Internal Medicine 8, no. 7 (1993): 374-77; D.J. Mazur and J.F. Merz, "How Age, Outcome Severity, and Scale Influence General Medicine Clinic Patients' Interpretations of Verbal Probability Terms" (See comments), Journal of General Internal Medicine 9 (1994): 268-71.

50. Miles, Koepp, and Weber, "Advance End-of-Life Treatment Planning." 517.

51. Ott, "Advance Directives."pp. 514,

52. J.J. Christensen-Szalanski, "Discount Functions and the Measurement of Patients' Values: Women's Decisions during Childbirth," Medical Decision Making 4, no. 1 (1984): 47-58.

53. R.M. Gready et al., "Actual and Perceived Stability of Preferences for Life-Sustaining Treatment," Journal of Clinical Ethics 11, no. 4 (2000): 334-46.

54. A. Upadya et al, "Patient, Physician, and Family Member Understanding of Living Wills," American Journal of Respiratory and Critical Care Medicine 166 (2002): 1433.

55. W. Sheed, In Love with Daylight: $A$ Memoir of Recovery (New York: Simon and Schuster, 1995): 14.

56. Gready et al., "Actual and Perceived Stability of Preferences for Life-Sustaining Treatment"; J.T. Berger and D. Majerovitz, "Stability of Preferences for Treatment among Nursing Home Residents," Gerontologist 28, no. 2 (1998): 217-23; S. Carmel and E. Mutran, "Stability of Elderly Persons' Expressed Preferences regarding the Use of Life-Sustaining Treatments," Social Science and Medicine 49, no. 3 (1999): 303311; M. Danis et al., "Stability of Choices about Life-Sustaining Treatments," Annals of Internal Medicine 120, no. 7 (1994): $567-$ 73; P.H. Ditto et al., "A Prospective Study of the Effects of Hospitalization on Life-Sustaining Treatment Preferences: Context Changes Choices," Unpublished manuscript; P.H. Ditto et al., "The Stability of Older Adults' Preferences for Life-Sustaining Medical Treatment," Unpublished manuscript; E.J. Emanuel, "Commentary on Discussions about Life-Sustaining Treatments," Journal of Clinical Ethics 5, no. 3 (1994): 250-51; L.L. Emanuel et al., "Advance Directives: Stability of Patients' Treatment Choices," Archives of Internal Medicine 154 (1994): 209-217; M.A. Everhart and R.A. Pearlman, "Stability of Patient Preferences regarding Life-Sustaining Treatments," Chest 97 (1990): 159-64; L. Ganzini et al., "The Effect of Depression Treatment on Elderly Patients' Preferences for Life-Sustaining Medical Therapy," American Journal of Psychiatry 151, no. 11 (1994): 1631-36; N. Kohut et al., "Stability of Treatment Preferences: Although Most Preferences Do Not Change, Most People Change Some of their Preferences," Journal of Clinical Ethics 8, no. 2 (1997): 124-35; M.D. Silverstein et al., "Amyotrophic Lateral Sclerosis and Life-Sustaining Therapy: Patients' Desires for Information, Participation in Decision Making, and Life-Sustaining Therapy," Mayo Clinic Proceedings 66 (1991): 906-913; J.S. Weissman et al., "The Stability of Preferences for Life-Sustaining Care among Persons with AIDS in the Boston Health Study," Medical Decision Making 19 (1999): 16-26; K.M. Coppola et al., "Are Life-Sustaining Treatment Preferences Stable over Time? An Analysis of the Literature," unpublished manuscript.

57. Coppola et al., "Are Life-Sustaining Treatment Preferences Stable over Time?"

58. Danis et al., "Stability of Choices about Life-Sustaining Treatments"; Ditto et al., "A Prospective Study of the Effects of Hospitalization"; Weissman et al., "The Stability of Preferences for Life-Sustaining Care."

59. Ditto et al., "A Prospective Study of the Effects of Hospitalization."

60. H.M. Chochinov et al., "Will to Live in the Terminally Ill," Lancet 354 (1999): 816,818

61. D.T. Gilbert and T.D. Wilson, "Miswanting: Some Problems in the Forecasting of Future Affective States," in Feeling and Thinking: The Role of Affect in Social Cognition, ed. J.P. Forgas (New York: Cambridge University Press, 2000): 178-97; C.H. Griffith 3rd et al., "Knowledge and Experience with Alzheimer's Disease: Relationship to Resuscitation Preference," Archives of Family Medicine 4, no. 9 (1995): 780-84; T.M. Osberg and J.S. Shrauger, "Self-prediction: Exploring the Parameters of Accuracy," Journal of Personality and Social Psychology 51, no. 5 (1986): 1044-57.

62. Griffith 3rd et al., "Knowledge and Experience with Alzheimer's Disease."

63. Gilbert and Wilson, "Miswanting."

64. D. Kahneman and J. Snell, "Predicting a Changing Taste: Do People Know What They Will Like?" Journal of Behavioral Decision Making 5, no. 3 (1992): 187-200.

65. Gilbert and Wilson, "Miswanting."

66. Ibid.

67. G. Loewenstein and D. Schkade, "Wouldn't It Be Nice? Predicting future feelings," in Hedonic Psychology: Scientific Approaches to Enjoyment, Suffering and Wellbeing," ed. N. Schwartz and D. Kahneman (New York: Russell Sage Foundation, 1997).

68. D. Schkade, Does Living in California Make People Happy? A Focusing Illusion in Judgements of Life Satisfaction," Psychological Science 9 (1998): 340-46.

69. Loewenstein and Schkade, "Wouldn't It Be Nice?"

70. A.S. Brett, "Limitations of Listing Specific Medical Interventions in Advance Directives," JAMA 266 (1991): 825-28.

71. I.S. Kirsch et al., Adult Literacy in America: A First Look at the Results of the National Adult Literacy Survey, U.S. Department of Education; August 1993; NCES 93275.

72. Cox and Sachs, "Advance Directives and the Patient Self-Determination Act"; Miles, Koepp, and Weber, "Advance Endof-Life Treatment Planning"; Silveira et al., "Patient's Knowledge of Options at the End of Life"; Coppola et al., "Perceived Benefits and Burdens of Life-Sustaining Treatments."

73. Pope, "The Maladaptation of Miranda to Advance Directives." pp. 139, 165-66.

74. D.J. Doukas and L.B. McCullough, "The Values History: The Evaluation of the Patient's Values and Advance Directives," Journal of Family Practice 32, no. 2 (1991): 145-53.

75. Lochner v. New York N. 198 U.S. 45: Supreme Court of the United States; 1905.

76. H.J. Silverman et al., "Implementation of the Patient Self-Determination Act in a Hospital Setting: An Initial Evaluation," Archives of Internal Medicine 155, no. 5 (1995: 502-510.

77. Roe et al., "Durable Power of Attorney for Health Care."

78. R.S. Morrison et al., "The Inaccessibility of Advance Directives on Transfer 
from Ambulatory to Acute Care Settings," JAMA 274 (1995): 478-82.

79. Ibid.

80. M. Danis et al., "A Prospective Study of the Impact of Patient Preferences on LifeSustaining Treatment and Hospital Cost," Critical Care Medicine 24, 11 (1996): 181117.

81. J.A. Druley et al., "Physicians' Predictions of Elderly Outpatients' Preferences for Life-Sustaining Treatment," Journal of Family Practice 37 (1993): 469-75; J. Hare, C. Pratt, and C. Nelson, "Agreement between Patients and Their Self-Selected Surrogates on Difficult Medical Decisions," Archives of Internal Medicine 152, no. 5 (1992): 10491054; P.M. Layde et al., "Surrogates' Predictions of Seriously Ill Patients' Resuscitation Preferences," Archives of Family Medicine 4, no. 6 (1995): 518-23; J.G. Ouslander, A.J. Tymchuk, and B. Rahbar, "Health Care Decisions among Elderly Long-term Care Residents and Their Potential Proxies," Archives of Internal Medicine 149 no. 6 (1989): 1367-72; A.B. Seckler et al., "Substituted Judgment: How Accurate Are Proxy Predictions?" Annals of Internal Medicine 115 (1991): 92-98; D.P. Sulmasy et al., "The Accuracy of Substituted Judgments in Patients with Terminal Diagnoses," Annals of Internal Medicine 128, no. 8 (1998): 621-29; R.F. Uhlmann, R.A. Pearlman, and K.C. Cain, 'Physicians' and Spouses' Predictions of Elderly Patients' Resuscitation Preferences," Journal of Gerontology 43, no. 5 (1988): M115-M121; R.F. Uhlmann, R.A. Pearlman, and K.C. Cain, "Understanding of Elderly Patients' Resuscitation Preferences by Physicians and Nurses," Western Journal of Medicine 150 (1989): 705-707; N.R. Zweibel and C.K. Cassell, "Treatment Choices at the End of Life: A Comparison of Decisions by Older Patients and Their Physician-Selected Proxies," Gerontologist 29, no. 5 (1989): 615-21.

82. L. Emanuel, "The Health Care Directive: Learning How to Draft Advance Care Documents," Journal of the American Geriatrics Society 39, no. 12 (1991): 122128; P.H. Ditto et al., "Fates Worse than Death: The Role of Valued Life Activities in Health-State Evaluations," Health Psychology 15, no. 5 (1996): 332-43.

83. K.M. Coppola et al., "Accuracy of Primary Care and Hospital-based Physicians' Predictions of Elderly Outpatients' Treatment Preferences with and without Advance Directives," Archives of Internal Medicine 161, no. 3 (2001): 431-40.

84. Ibid.

85. M.D. Goodman, M. Tarnoff, and G.J. Slotman, "Effect of Advance Directives on the Management of Elderly Critically Ill Patients," Critical Care Medicine 26, no. 4 (1998): 701-704.
86. Morrison et al., "The Inaccessibility of Advance Directives."

87. M. Danis and J.M. Garrett, "Advance Directives for Medical Care: Reply," NEJM 325 (1991): PP NO?.

88. J. Katz, "Informed Consent-A Fairy Tale? Law's vision," University of Pittsburgh Law Review 39, no. 2 (1977): 137-74; C.H. Braddock 3rd et al., "Informed Decision Making in Outpatient Practice: Time to Get Back to Basics," JAMA 282, no. 24 (1999): 2313-20.

89. C.E. Schneider, "The Best-Laid Plans," Hastings Center Report 30, no. 4 (2000): 24-25; C.E. Schneider, "Gang Aft Agley," Hastings Center Report 31, no. 1 (2001): 27-28.

90. Teno et al., "Do Advance Directives Provide Instructions that Direct Care?"

91. W.R. Mower and L.J. Baraff, "Advance Directives: Effect of Type of Directive on Physicians' Therapeutic Decisions," Archives of Internal Medicine 153 (1993): 375, 378.

92. J. Lynn, "Learning to Care for People with Chronic Illness Facing the End of Life," JAMA 284 (2000): 2508-09.

93. J. Teno et al., "The Illusion of Endof-Life Resource Savings with Advance Directives. SUPPORT Investigators. Study to Understand Prognoses and Preferences for Outcomes and Risks of Treatment," Journal of the American Geriatrics Society 45, no. 4 (1997): 513-18.

94. A. Fagerlin et al., "Projection in Surrogate Decisions about Life-Sustaining Medical Treatments," Health Psychology 20, no. 3 (2001): 166-75.

95. J. Virmani, L.J. Schneiderman, and R.M. Kaplan, "Relationship of Advance Directives to Physician-Patient Communication," Archives of Internal Medicine 154 (1994): 909-913.

96. J.A. Tulsky, M.A. Chesney, B. Lo, "How Do Medical Residents Discuss Resuscitation with Patients?" Journal of General Internal Medicine 10 no. 8 (1995): 436-42.

97. Tulsky et al., "Opening the Black Box.” pp. 441, 445.

98. P.H. Ditto et al., "Advance Directives as Acts of Communication: A Randomized Controlled Trial, Archives of Internal Medicine 161, no. 3 (2001): 421-30.

99. R. Baker et al., "Family Satisfaction with End-of-Life Care in Seriously Ill Hospitalized Adults," Journal of the American Geriatrics Society 48, no 5 (suppl) (2000): S61-S69.

100. V.P. Tilden et al., "Family Decisionmaking to Withdraw Life-Sustaining Treatments from Hospitalized Patients," Nursing Researd 50, no. 2 (2001): 105-115.

101. Miles, Koepp, and Weber, "Advance End-of-Life Treatment Planning."
102. Teno et al., "The Illusion of End-ofLife Resource Savings with Advance Directives"; E.J. Emanuel and L.L. Emanuel, "The Economics of Dying: The Illusion of Cost Savings at the End of Life," NEJM 330 (1994): 540-44; L.J. Schneiderman et al., "Effects of Offering Advance Directives on Medical Treatments and Costs," Annals of Internal Medicine 117, no. 7 (1992): 599606.

103. J. Sugarman et al., "The Cost of Ethics Legislation: A Look at the Patient Self-Determination Act," Kennedy Institute of Ethics Journal 3, no. 4 (1993): 387-99.

104. Pope, "The Maladaptation of Miranda to Advance Directives." pp. 139, 167.

105. Yates and Glick, "The Failed Patient Self-Determination Act"; Sugarman et al., "The Cost of Ethics Legislation." 